
de spécialité du 32 e congrès de la SAES

\title{
Bulletin de naissance
}

\section{Michel Perrin}

\section{(2) OpenEdition}

\section{Journals}

Édition électronique

URL : http://journals.openedition.org/asp/4353

DOI : $10.4000 /$ asp.4353

ISSN : 2108-6354

Éditeur

Groupe d'étude et de recherche en anglais de spécialité

\section{Édition imprimée}

Date de publication : 1 mars 1993

Pagination : vii-ix

ISSN : 1246-8185

\section{Référence électronique}

Michel Perrin, «Bulletin de naissance », ASp [En ligne], 1 | 1993, mis en ligne le 07 mars 2014, consulté le 22 septembre 2020. URL : http://journals.openedition.org/asp/4353 ; DOI : https://doi.org/10.4000/ asp.4353

Ce document a été généré automatiquement le 22 septembre 2020.

Tous droits réservés 


\title{
Bulletin de naissance
}

\author{
Michel Perrin
}

1 Depuis sa fondation en 1977, le GERAS, Groupe d'étude et de recherche en anglais de spécialité tient colloque à peu près annuellement. Depuis plus d'une décennie également, l'atelier «Langue de spécialité » des congrès annuels de la SAES rassemble un nombre croissant de communications.

2 Ces deux manifestations donnent régulièrement lieu à la publication d'Actes dont seulement ceux de 1989, 1990 et 1991 sont encore disponibles (en petit nombre). Un tel mode d'édition, sous forme de volumes indépendants et de présentation très diverse est peu propice à la diffusion la plus large possible des travaux de ceux qu'intéresse la recherche en langue de spécialité.

3 Cette voie de recherche a reçu, en 1991, l'aval officiel de la Direction de la recherche et des études doctorales, par habilitation donnée aux Universités de Bordeaux 2, Toulouse 1 et Montpellier 3, appuyées par celles de Chambéry, Compiègne, Lyon 1, Paris 5 et par le réseau du GERAS, à décerner le DEA de Langue anglaise des spécialités scientifiques et techniques: méthodologie de la recherche linguistique, didactique, culturelle, technologique.

4 Il suffit de parcourir le sommaire du présent volume pour s'apercevoir que féconds également se révèlent être les quatre axes d'exploration retenus pour le sous-titre cidessus.

5 Le temps paraît mûr pour lancer, en France, le pendant de ce qu'est dans le monde anglophone la revue English for Specific Purposes. Tous les anglicistes qui ont choisi la langue de spécialité comme terrain de recherche disposent désormais, avec ASp, de l'organe régulier d'expression qui leur faisait défaut.

6 Cette première livraison est uniquement constituée des Actes du $13^{\mathrm{e}}$ colloque du GERAS tenu à Montpellier en février 1992 et de ceux de l'atelier SAES de Strasbourg en mai 1992. Dès le numéro 2, dont la sortie est prévue pour le début de l'été 1993, quelques articles sélectionnés pourront venir s'ajouter au texte des communications prononcées lors du $14^{\mathrm{e}}$ colloque du GERAS de Grenoble (4-8 mars 1993). Par la suite, il conviendra 
de décider de la périodicité de la revue et de la taille de chacun des numéros : toutes les bonnes volontés seront les bienvenues, pour aider au travail du comité de rédaction.

7 Que tous ceux qui le souhaiteront veuillent donc bien considérer le présent bulletin de naissance comme un appel à contribution. ASp se donne pour mission de faire mieux connaître, et reconnaître, le travail considérable qui s'accomplit désormais dans le quatrième champ d'action de l'anglistique : aux côtés des domaines traditionnels de la littérature, de la linguistique et de la civilisation, à leur carrefour aussi, la langue de spécialité devient un enjeu majeur à mesure que crô̂t, dans nos établissements d'enseignement supérieur, la demande de formation approfondie.

Chance et défi pour la génération montante des jeunes chercheurs et professeurs : par la voix de l'actuel président du GERAS s'expriment ici à leur intention les vœux chaleureux des quelques pionniers qui lancèrent la discipline. Pour ceux qu'aura marqués une ascendance pyrénéenne, ASp évoquera la vision d'une vallée riante qui mène à des sommets (rendus désormais célèbres par le combat inégal des derniers ours et des perceurs de tunnel); d'autres se contenteront du mordant et du piquant de la variété anglais de l'aspic, voire de la frondaison dynamique du tremble... Richesse de la polysémie : nous choisirons d'y voir l'augure d'une fertile et longue vie.

\section{BIBLIOGRAPHIE}

Costa, F. et R. Tixier (dir.). 1991. Civilisations 4 Actes du 10 colloque du GERAS à Toulouse 11-12 mai 1989 « Langues, vidéo, informatique ». Toulouse : Université de Sciences sociales.

Perrin, M. (dir.). 1990. Actes du $11^{e}$ colloque du GERAS à Bordeaux « Langue de spécialité, langue pour le spécialiste ». Bordeaux : GERAS Éditeur.

Perrin, M. (dir.). 1991. Actes du $12^{e}$ colloque du GERAS à Compiègne et de l'atelier "Langue de spécialité » du $31^{e}$ congrès de la SAES à Aix-en-Provence. Bordeaux : GERAS Éditeur.

\section{AUTEUR}

\section{MICHEL PERRIN}

Professeur à l'Université Victor Segalen Bordeaux 2. 